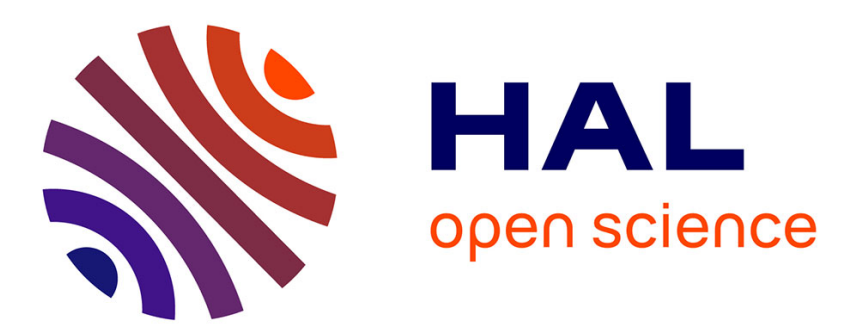

\title{
Mediation of host selection and oviposition behavior in the diamondback moth Plutella xylostella and its predator Chrysoperla carnea by chemical cues from cole crops.
}

- Reddy G.V.P., Elisabeth Tabone, - Smith M.T.

\section{- To cite this version:}

- Reddy G.V.P., Elisabeth Tabone, - Smith M.T.. Mediation of host selection and oviposition behavior in the diamondback moth Plutella xylostella and its predator Chrysoperla carnea by chemical cues from cole crops.. Biological Control, 2004, 29, pp.270-277. hal-02672133

\section{HAL Id: hal-02672133 \\ https://hal.inrae.fr/hal-02672133}

Submitted on 31 May 2020

HAL is a multi-disciplinary open access archive for the deposit and dissemination of scientific research documents, whether they are published or not. The documents may come from teaching and research institutions in France or abroad, or from public or private research centers.
L'archive ouverte pluridisciplinaire HAL, est destinée au dépôt et à la diffusion de documents scientifiques de niveau recherche, publiés ou non, émanant des établissements d'enseignement et de recherche français ou étrangers, des laboratoires publics ou privés. 


\title{
Mediation of host selection and oviposition behavior in the diamondback moth Plutella xylostella and its predator Chrysoperla carnea by chemical cues from cole crops
}

\author{
G.V.P. Reddy, ${ }^{\mathrm{a}, *}$ E. Tabone, ${ }^{\mathrm{b}}$ and M.T. Smith ${ }^{\mathrm{c}}$ \\ agricultural Experiment Station, College of Agriculture and Life Sciences, University of Guam, Mangilao, GU 96923, USA \\ ' INRA, Entomologie et Lutte Biologique, $37 \mathrm{Bd}$ du Cap. Antibes F-06606, France \\ ' USDA, ARS, Beneficial Insect Introduction Research Unit, University of Delaware, 501 S. Chapel, St. Newark, DE 19713-3814, USA
}

Received 28 January 2003; accepted 15 July 2003

\begin{abstract}
Host plant-mediated orientation and oviposition by diamondback moth (DBM) Plutella xylostella (L.) (Lepidoptera: Yponomeutidae) and its predator Chrysoperla carnea Stephens (Neuroptera: Chrysopidae) were studied in response to four different brassica host plants: cabbage, (Brassica oleracea L. subsp. capitata), cauliflower (B. oleracea L. subsp. botrytis), kohlrabi $(B$. oleracea L. subsp. gongylodes), and broccoli ( $B$. oleracea L. subsp. italica). Results from laboratory wind tunnel studies indicated that orientation of female DBM and $C$. carnea females towards cabbage and cauliflower was significantly greater than towards either broccoli or kohírabi plants. However, DBM and C. carnea males did not orient towards any of the host plants. In no-choice tests, oviposition by DBM did not differ significantly among the test plants, while $C$. carnea layed significantly more eggs on cabbage, cauliflower, and broccoli than on kohlrabi. However, in free-choice tests, oviposition by DBM was significantly greater on cabbage, followed by cauliflower, broccoli, and kohlrabi, while $C$. carnea preferred to oviposit on cabbage and cauliflower, followed by broccoli and kohlrabi. The predation rates of DBM by $C$. carnea on kohlrabi and broccoli were not significantly different from one another, but were significantly higher than that on cabbage and cauliflower. When two types of plant, intact and injured, were

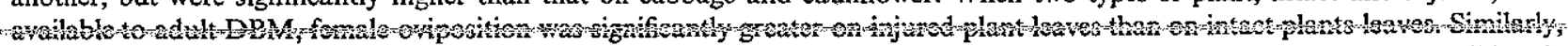
C. carnea oviposition was significantly greater on injured plant leaves than on intact leaves. Implications regarding the possible role of green leaf volatiles in host selection/preference, as well as in tritropic interactions, are discussed.
\end{abstract}

(c) 2003 Elsevier Inc. All rights reserved.

Keywords: Plutella xylostella; Chrysoperla carnea; Host plant preference; Oviposition; Cabbage; Caulifiower; Broccoli; Kohlrabi

\section{Introduction}

The diamondback moth (DBM), Plutella xylostella (L.) (Lepidoptera: Yponomeutidae), is the most important pest of cultivated brassicas worldwide (Talekar and Shelton, 1993). DBM occurs throughout the year wherever its host plants are grown. DBM larvae feed on all plants in the crucifer family (canola, Brassica campestris L. and Brassica napus L. mustard, Brassica juncea L.), cole crops (cabbage, Brassica oleracea L. subsp. capitata, cauliflower B. oleracea L. subsp. Botrytis, and

"Corresponding author. Fax: 1-671-734-6842.

E-mail-address:-reddy@guam-uog-edu-(G.V.R.Reddy). kohlrabi $B$. oleracea L. subsp. gongylodes) and on several green house plants. Because of the widespread use of insecticides to control DBM, it has developed resistance to numerous insecticides, including several Bacillus thuringiensis (Bt) products (Tabashnik et al., 1992; Tabashnik, 1994; Talekar and Shelton, 1993). This has led to a renewed interest in developing alternatives to the use of insecticides, such as biological control and development of resistant plants (Thomas and Waage, 1996).

Chrysoperla spp. lacewings (Neuroptera: Chrysopidae) are considered to be one of the most effective generalist predators (McEwen et al., 2001; New, 1975), feeding-on eggs and young-caterpillars, aphids, spider 
mites, scales, psylla, mealybugs, whiteflies, thrips, leafhoppers, and other soft-bodied prey (Canard et al., 1984; New, 1988). Lacewings are highly predacious and cannibalistic as larvae (Nordlund, 1993), using their channeled mandibles to inject digestive enzymes into their prey and then to suck out body fluids (Olkowski et al., 1991). Adult lacewings generally feed solely on nectar, pollen, and honeydew, although a few are predatory (Coppel and Mertins, 1977). Experimental field research has demonstrated that lacewings are effective predators of aphids on red peppers (Hassan, 1976), of mites on apples (Miszczak and Niemczyk, 1978), and of leaf hoppers on grapes (Daane et al., 1993). Effective control can be achieved by releasing relatively large numbers of lacewing larvae. For example, Daane and Yokota (1997) used between 1 and 16 lacewings per plant in reducing the pest populations in vineyard. Among these predators, Chrysoperla carnea Stephens has been used in an integrated pest management (IPM) program to control DBM in cabbage (Reddy and Guerrero, 2000a). Reddy et al. (2002) observed that male and female $C$. carnea were highly attracted to the DBM pheromone blend and to the pheromone blend devoid of $Z 11-16: \mathrm{OH}$, as well as to the DBM larval frass, while among the green leaf volatiles of cabbage ( $B$. oleracea subsp. capitata), only Z3-6:Ac elicited responses in a Y-tube olfactometer.

In phytophagous insects, the behavioral process leading to host location and acceptance for oviposition or feeding may include orientated movement from a distance in response to plant cues (Bernays and Chapman, 1994; Kennedy, 1965). Information on host selection behavior of DBM and response of females to various host plants are important for the ceveropinen of IPM systems. Similarly host plants and ovipositional preferences of $C$. carnea play a vital role in the effective use of this predator to control DBM on different host plants. Therefore, the present study was aimed at investigating the role of chemical cues in the host selection and oviposition behavior of DBM and its predator $C$. carnea on cole crops.

\section{Materials and methods}

DBM and $C$. carnea larvae were collected from a field of summer mustard ( $B$. juncea L.) grown without the use of pesticides. Before experimentation, several generations of the host and predator were reared in the laboratory.

\subsection{Rearing of $D B M$}

Rearing of immature DBM was carried out in polyester gauze cages $(50 \times 30 \times 25 \mathrm{~cm})$ at $25^{\circ} \mathrm{C}, 60 \% \mathrm{RH}$, and a 16:8 (L:D) h photoperiod. Each cage contained a
5- to 6-week-old mustard plant seedling, two small cups of honey/water solution $(10 \% \mathrm{w} / \mathrm{v})$ for adult feeding, and 50 pair of adult DBM. Plants were replaced daily. After oviposition, seedlings were transferred to another cage for mass rearing of the larvae. Fresh plants were provided every $2-3$ days for larval feeding. This procedure consistently produced large numbers of various stages of DBM.

\subsection{Rearing of C. carnea}

Chrysoperla carnea were reared on larvae of DBM at $28 \pm 2{ }^{\circ} \mathrm{C}, 60-65 \% \mathrm{RH}$, and a $16: 8$ (L:D) h photoperiod as described in a previous study (Reddy et al., 2002). $C$. carnea eggs were individually placed in plastic cups $(6 \mathrm{~cm}$ long $\times 3 \mathrm{~cm}$ ID), and after hatching larvae were fed young DBM larvae feeding on mustard leaves. Upon emergence, newly emerged $C$. carnea adults were collected daily, supplied with honey:fructose:protinex:water at 1:1:1:1 by volume and transferred to acrylic cages $(28 \mathrm{~cm}$ diameter) for oviposition. Male and female $C$. carnea, 3-6 days old, were used for the tests. Although adult male and female $C$. carnea are similar in overall size and appearance, they were sexed by looking closely at the ventral surface of the tip of the abdomen using a $10 \times$ hand lens. Males have a small rounded capsule, flanked by two small projections, while females have an oval area bounding a longitudinal slit.

\subsection{Plants}

Plant species used in the experiments included cab-

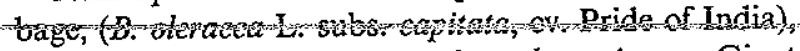
cauliflower $(B$. oleracea L. subsp. botrytis, cv. Giant Snowball), kohlrabi (B. oleracea L. subsp. gongylodes, cv. Purple Vienna), and broccoli ( $B$. oleracea L. subsp. italica, cv. Italian Sprouting De Cicco). Seedlings were raised in a greenhouse nursery $\left(25-30^{\circ} \mathrm{C}, 60-80 \% \mathrm{RH}\right.$, 16:8 (L:D) $\mathrm{h}$ photoperiod) and each transplanted individually to a pot filled with a mixture of $3 \mathrm{~kg}$ sand, $2 \mathrm{~kg}$ farm yard manure (FYM), and $2 \mathrm{~kg}$ loamy clay soil ( $\mathrm{pH}$ 7.3 , available $\mathrm{P}_{2} \mathrm{O}_{5}, 5.3 \mathrm{mg} / 100 \mathrm{~g} ; \mathrm{K}_{2} \mathrm{O}, 7.5 \mathrm{mg} / 100 \mathrm{~g}$ ), and supplied with $1.5 \mathrm{~g}$ nitrogen applied as $\mathrm{NH}_{4} \mathrm{NO}_{3}$, $2.0 \mathrm{~g}$ phosphorous as $\mathrm{Ca}\left(\mathrm{H}_{2} \mathrm{PO}_{4}\right)$, and $3.0 \mathrm{~g}$ potassium as $\mathrm{KCL}$ and $\mathrm{K}_{2} \mathrm{SO}_{4}(50 / 50)$ and magnesium as $\mathrm{MgSo}_{4}$. All fertilizer compounds were mixed in the dry soil as solutions except for $\mathrm{P}$, which was added as pure salt. Moisture content was adjusted at about $60 \%$ of capacity and held at this level by irrigating during the experiment. The plants were grown under natural light and temperature conditions. The plants were covered with fine mesh netting to protect them from other possible insect attack. For the different experiments, 40-day-old plants were used since DBM infestations are generally high on -such plants. 
2.4. Orientation of adult DBM and C. carnea to different host plants

The wind tunnel used in this study has been previously described by Ballal and Singh (1999) to record the orientation movement of predators to different host plants. The wind tunnel consisted of six chambers (each measuring $30 \times 30 \times 30 \mathrm{~cm}$ ) made of transparent Perspex chambers. One test chamber was placed in the center with the five outer bait chambers connected to the central chamber by means transparent tubes $(130 \mathrm{~cm}$ in length and $8.0 \mathrm{~cm}$ in diameter) made of polyester film ( $175 \mu \mathrm{m}$ thick). The tubes were connected to the inner holes of the bait chambers. The outer holes of the bait chambers were covered with pieces of muslin cloth fastened with rubber bands. Table fans $(20 \mathrm{~cm}$ diameter) were positioned in front of the outer holes of each bait chamber and a controlled airflow passed from the bait chambers (containing host plants) to the test chamber. These choice tests were carried out in daylight, at $28 \pm 2{ }^{\circ} \mathrm{C}$ and $70 \% \mathrm{RH}$, and wind velocity was maintained $1 \mathrm{~m} / \mathrm{s}$ in the tunnel.

Unmated, 1-day-old adult DBM or C. carnea (five males and five females) were released into the test chamber and allowed to acclimatize for $2 \mathrm{~h}$. Live intact plants of cabbage, cauliflower, broccoli, and kohlrabi were placed separately in each outer chamber, while one chamber was maintained as control without any host plant. The plants were screened from the insects to measure odor-based orientation rather than contact cues. After $12 \mathrm{~h}$ the number of adults in each chamber was counted and the percentage of adults moving to each plant was calculated. The experiment was repeated

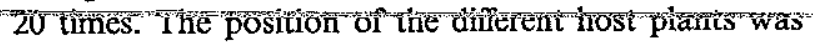
rotated by $90^{\circ}$ after each replicate in order to avoid light source related bias. The wind tunnel was thoroughly washed with soap and water, rinsed in $70 \%$ ethanol, and dried after every three replicates.

\subsection{Ovipositional preference studies of $D B M$ and C. carnea to different host plants}

These studies were carried out on four different cole crops (cabbage, cauliflower, broccoli, and kohlrabi) using no-choice and free-choice tests. In no-choice tests, the response of DBM or $C$. carnea was tested using only a single host plant. Live intact plants, 5-6 weeks old, of cabbage, cauliflower, broccoli, and kohlrabi were placed separately in a cage (measuring $30 \times$ $30 \times 30 \mathrm{~cm}$ ) with cloth sleeves in the sides for introducing adults. The DBM adults were fed with honey/ water solution $(10 \% \mathrm{w} / \mathrm{v})$ while $C$. carnea were fed with honey:fructose:protinex:water at $1: 1: 1: 1$ by volume. Two mated females of 1-day-old DBM or $C$. carnea were released into each cage with host plants.
The plants were removed after $48 \mathrm{~h}$, and the numbers of eggs laid on each plant were counted. The response of DBM or $C$. carnea to different host plants was also studied under free choice of host plants using cages (measuring $120 \times 90 \times 60 \mathrm{~cm}$ ). Live intact plants, 5-6 weeks. old, of cabbage, cauliflower, broccoli, and kohlrabi were placed together in a cage and ten mated females of DBM or $C$. carnea were released into the cage. The plants were removed after $48 \mathrm{~h}$, and the numbers of eggs laid on each host plant were counted. Both no-choice and free-choice tests were repeated 20 times for DBM and C. carnea.

\subsection{Predation rate of $C$. carnea on different host plants}

Live intact plants, 5-6 weeks old, one plant each of cabbage, cauliffower, broccoli, and kohlrabi were placed together in a cage (measuring $120 \times 90 \times 60 \mathrm{~cm}$ ). One hundred second instar DBM larvae were inoculated on each host plant and allowed to feed for $3 \mathrm{~h}$. Ten 3-dayold $C$. carnea larvae were released randomly in between the host plants. After $12 \mathrm{~h}$, the numbers of DBM larvae were counted from each plant and the rate of predation was scored. This experiment was replicated 20 times.

\subsection{Ovipositional site preference by $D B M$ and $C$. carnea on injured and uninjured cabbage plants}

This experiment was performed in a cage (measuring $30 \times 30 \times 30 \mathrm{~cm})$ on cabbage plants to observe where eggs are laid on the plants. One live intact healthy and one injured plant were placed in each cage. Injured

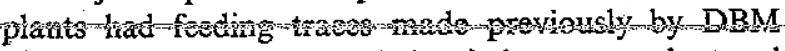
larvae (ca. 25-30 holes made by six larvae per plant and larvae were removed prior to the test). Ten mated females of 1-day-old DBM or C. carnea were released in each cage containing both intact and injured cabbage plants. The DBM adults were fed honey/water solution $(10 \% \mathrm{w} / \mathrm{v})$ while $C$. carnea were fed with honey:fructose:protinex:water at 1:1:1:1 by volume. The plants were removed after $48 \mathrm{~h}$, and the numbers of eggs laid on each part of each host plant were counted. This experiment was replicated 20 times for DBM and C. carnea.

The data from the windtunnel studies and from predation rate test were analyzed using the repeated measure ANOVA and presented as percentages. The data from free-choice oviposition experiments and from oviposition preference on cabbage test were anylyzed using the Hotelling's $t$ test based on the proportion of eggs laid on each plant. The data from the no-choice oviposition experiments were analyzed using analysis of variance and means were separated using Tukey honestly significant difference (HSD) multiple comparison test-(Steel and Torrie, 1980): 


\section{Results}

\subsection{Host plant preference of $D B M$ and $C$. carnea}

Orientational difference of male DBM and male C. carnea to different host plants was non-significant (Table 1). Significantly more adult female DBM and female $C$. carnea oriented to cabbage ( 41 and $37 \%$, respectively) and cauliflower (34 and $29 \%$, respectively) than to broccoli (17 and $11 \%$, respectively) and kohlrabi (5 and 13\%, respectively). The percentage of adult female DBM that oriented to kohlrabi and the percentage of adult female $C$. carnea that oriented to broccoli and kohlrabi were not significantly different from the percentage that oriented to the control.

\subsection{Ovipositional preference of $D B M$ and $C$. carnea}

In no-choice tests (Table 2), both DBM and C. carnea females laid more eggs on cabbage (72.4 and 38.3, respectively) and cauliflower ( 67.3 and 41.5 , respectively) than on broccoli and kohlrabi. However, there were no statistically significant differences in oviposition by DBM among host plants. On the other hand, C. carnea oviposited significantly fewer eggs on kohlrabi than on the other three host plants. In free-choice tests (Table 2), female DBM oviposition was significantly greater on cabbage than on cauliflower, broccoli, and kohlrabi, while oviposition on cauliflower and broccoli was not significantly different but significantly greater than on kohlrabi. However, female $C$. carnea oviposition was significantly greater on cabbage and cauliflower than on broccoli and kohlrabi.

\subsection{Predation rate of $C$. carnea on different host plants}

The predation rate by $C$. carnea was significantly greater on kohlrabi $(94.6 \%)$ and broccoli $(82.2 \%)$ than on cauliflower (48.4\%) and cabbage (52.8\%) (Fig. 1). However, predation rate was not significantly different on kohlrabi and broccoli.

\subsection{Ovipositional site preference of $D B M$ and $C$. carnea}

When two types of cabbage plants were available to adult DBM, female oviposition was significantly greater on injured than on intact plant leaves (Table 3). When DBM laid eggs on intact cabbage plants, they preferred

Table 1

Host plant preference of DBM and $C$. carnea to different cole crops

\begin{tabular}{|c|c|c|c|c|}
\hline \multirow[t]{3}{*}{ Host plants } & \multicolumn{4}{|c|}{ Percent (mean $\pm S E$ ) of adults moving towards plants } \\
\hline & \multicolumn{2}{|l|}{ DBM } & \multicolumn{2}{|l|}{ C. carnea } \\
\hline & Male & Female & Male & Female \\
\hline Cabt & $19 \pm 2.5 \mathrm{a}$ & $41 \pm 57 a$ & $22 \pm 2.6 \mathrm{a}$ & $37 \pm 7.3 \mathrm{a}$ \\
\hline Cauliflower & $20 \pm 1.5 a$ & $34 \pm 6.3 \mathrm{a}$ & $17 \pm 3.5 \mathrm{a}$ & $29 \pm 2.6 a$ \\
\hline Broccóli & $18 \pm 8.2 a$ & $\mathrm{TT}+3.6 \mathrm{~B}$ & Z1 & T194.40 \\
\hline Kohlrabi & $18 \pm 6.3 \mathrm{a}$ & $5 \pm 6.2 \mathrm{c}$ & $16 \pm 2.7 \mathrm{a}$ & $13 \pm 2.4 b$ \\
\hline Control & $25 \pm 2.7 \mathrm{a}$ & $3 \pm 3.3 \mathrm{c}$ & $24 \pm 5.1 \mathrm{a}$ & $10 \pm 2.6 \mathrm{~b}$ \\
\hline
\end{tabular}

${ }^{a}$ Means within a column followed by same letters are not significantly different $(P<0.05$; repeated measure ANOVA); mean of 20 replications, each replicate consist of five insects.

Table 2

Ovipositional preference of DBM and C. carnea to different cole crops

\begin{tabular}{|c|c|c|c|c|}
\hline \multirow[t]{3}{*}{ Host plants } & \multicolumn{4}{|c|}{ No. of eggs (mean $\pm S E$ ) laid during $48 \mathrm{~h}$ by } \\
\hline & \multicolumn{2}{|l|}{ DBM } & \multicolumn{2}{|l|}{ C. carnea } \\
\hline & No-choice & $\begin{array}{l}\text { Free- } \\
\text { choice }^{b}\end{array}$ & No-choice & $\begin{array}{l}\text { Free- } \\
\text { choice }^{b}\end{array}$ \\
\hline $\mathrm{Cabl}$ & $72.4 \pm$ & $98.5 t$ & $38.3 \pm 2.4 \mathrm{a}$ & 52.4 \\
\hline Cauliflower & $67.3 \pm 6.3 \mathrm{a}$ & $58.8 \pm 3.0 \mathrm{~b}$ & $41.5 \pm 5.3 a$ & $46.8 \pm 2.6 a$ \\
\hline Broccoli & $56.2 \pm 8.2 a$ & $53.3 \pm 3.8 \mathrm{~b}$ & $28.5 \pm 7.3 \mathrm{a}$ & $11.2 \pm 5.9 \mathrm{~b}$ \\
\hline Kohlrabi & $52.8 \pm 2.4 a$ & $12.6 \pm 1.2 \mathrm{c}$ & $6.5 \pm 3.4 b$ & $8.2 \pm 4 . \mathrm{Jb}$ \\
\hline
\end{tabular}

${ }^{a}$ Means within a column followed by same letters are not significantly different $(P<0.05$; Tukey HSD test); mean of 20 replications, each replicate consist of two insects.

${ }^{b}$ Means within a column followed by same letters are not significantly different $(P<0.01$; Hotelling's $t$ test); mean of 20 replications, each replicate consist or ten insects.

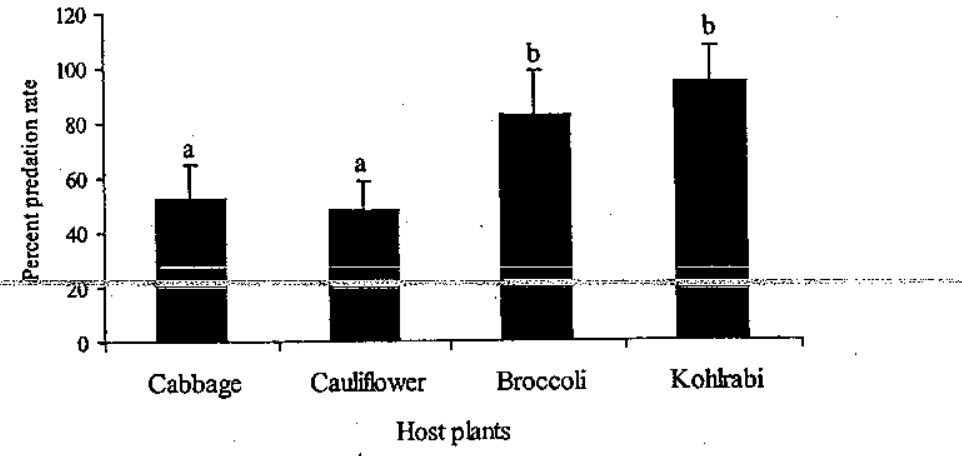

Fig. 1. The effect of the presence of DBM larvae on the predation rate by larvae of $C$. carnea. Bars with the same letters are not significantly different $(P<0.05$; repeated measure ANOVA); mean number $\pm \mathrm{SE}$ obtained from 20 replications, each replicate consists of 10 insects.

Table 3

Ovipositional site preference of DBM and C. carnea, on intact and injured cabbage plants

\begin{tabular}{|c|c|c|c|c|}
\hline \multirow{3}{*}{$\begin{array}{l}\text { Cabbage } \\
\text { plant parts }\end{array}$} & \multicolumn{4}{|c|}{ No. of eggs (mean $\pm S E$ ) laid by female of } \\
\hline & \multicolumn{2}{|l|}{ DBM } & \multicolumn{2}{|l|}{ C. carnea } \\
\hline & Intact & Injured & Intact & Injured \\
\hline Leaf & $28.3 \pm 2.4 b$ & $142.8 \pm 2.3 \mathrm{a}$ & $31.3 \pm 1.2 \mathrm{~b}$ & $62.8 \pm 5.2 \mathrm{a}$ \\
\hline Stem & $88.6 \div 4.2 \mathrm{a}$ & $32.8 \pm 5.2 \mathrm{~b}$ & $13.4 \pm 2.2 \mathrm{a}$ & $8.8 \pm 1.2 \mathrm{a}$ \\
\hline Other areas & $63.5 \pm 2.8 \mathrm{a}$ & $22.2 \pm 2.2 \mathrm{~b}$ & $4.8 \pm 4.5 \mathrm{a}$ & $2.2 \pm 2.3 \mathrm{a}$ \\
\hline
\end{tabular}

${ }^{a}$ Means for each insect type within a row followed by same letters are not significantly different ( $P<0.01$; HoteIling's $t$ test); mean of 20 replications, each replicate consists of 10 insects:-- 
to lay eggs on the stem and on other areas in the cage than on leaves. However on injured plants, significantly more eggs were laid on leaves than on the stem and other areas (Table 3). Similarly, when $C$. carnea laid eggs on intact plants, they preferred to lay more eggs on leaves of the intact cabbage plants than on other parts. However, $C$. carnea laid significantly more eggs on the injured plant leaves (mean of 62.8) as compared to leaves on intact plants (mean 31.3).

\section{Discussion}

Host plant chemical cues have a great influence on tritropic interactions (Vet and Dicke, 1992). The differences in orientation and egg laying on different host plants demonstrated that chemical cues mediated host plant selection in DBM and its predator, C. carnea. However, it is reported that a natural enemy initially seeks an environment and can recognize host plant factors, regardless of the presence or absence of its host (Ananthakrishnan, 1992).

In the present study it was observed that most female DBM orientated toward cabbage and cauliflower in a wind tunnel bioassay. Our results are somewhat comparable with those of Sant et al. (1982) who reported that DBM completed larval and pupal development in the shortest time on cauliffower, cabbage, and radish, and survival was greatest on these crops as compared to turnip and mustard. Host preference studies of DBM at the Asian Vegetable Research and Development Center, Shanhua (Taiwan) showed that larvae consumed less foliage and required more time to complete development

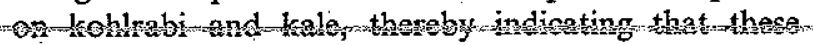
cruciferous crops were the least accepted hosts (Anonymous, 1987) when compared to other crops. Pivnick et al. (1994) found that female DBM moths are attracted to odors of $B$. juncea and $B$. napus seedlings in a Y-tube olfactometer. The DBM preferred to oviposit eggs on cabbage, which was followed by cauliflower, broccoli, and kohlrabi. This host preference may be due in part to different chemical cues possibly involved in the acceptance or rejection of potential hosts. DBM was shown to depend largely on the presence of stimulatory compounds and was not affected by deterrents that caused avoidance of plants in Pieris rapae (L.) (Lepidoptera: Pieridae) (Renwick and Radke, 1990). Charleston and Kfir (2000) observed in laboratory experiments that female DBM prefer to oviposit more eggs on $B$. juncea than on other Brassica species. However, their field trials indicated a higher larval infestation on broccoli, cauliflower, and cabbage than on Indian mustard. In the present study, the preference of DBM for cabbage and cauliflower over the other Brassica plants tested may be due in part to a wide range of compounds from these plants - which-may be-stimulatory-to-DBM-DBM-may- have more specific requirements for acceptance of cabbage for oviposition.

The predator used in the present study showed higher orientation towards cabbage and caulifiower than to other Brassica crops. According to the ideas by Vet and Dicke (1992), a generalist like $C$. carnea should not innately react to infochemicals in general. Hagen (1986) reported that lacewings were not nearly as attracted to the aphid honeydew if they did not have an associated plant volatile. Therefore, he concluded that predator attractants (wheast and Torulene) that worked in some fields (e.g., cotton) would not work in others unless the proper synomone was present. However, to our knowledge there are very few studies on the orientation of $C$. carnea to different crop plants. Volatiles emitted by eggplant (Solanum melongena L.), okra (Abelmoschus esculents L.), and pepper (Capsicum annum L.) that are damaged by spider mites (Tetranychus ludeni Zacher) (Acari: Tetranychidae) elicited a positive behavioral response from both $C$. carnea males and females in an olfactometer, while in contrast, $C$. carnea did not respond to volatiles from tomato (Lycopersicum esculentum Mill.) plants (Reddy, 2002). Extracts from the leaves of corn (Hybrid 3489) and catnip, Nepeta cataria L. elicited significant EAG responses in two predatory species, Coleomegilla maculata (Degeer) (Coleoptera: Coccinellidae) and $C$. carnea (Zhu et al., 1999). In the field, while many of the corn volatiles ( $\alpha$-terpineol, (Z)-3-hexenol, (Z)-3-hexenal, 1-octen-3-ol, 1-hexanol, $\beta$-farnesene, 2-phenylethanol, and $\beta$-caryophyllene) attracted equal numbers of both sexes of $C$. maculata, C. carnea adults were only attracted by 2-phenylethanol (Zhu et al., 1999). In a previous report, $\beta$-caryophyllene had been found to act as an attractant of $C$ carnea in the field (Flint et al., 1979). Cabbage plants are also known to attract parasitoids. For example, Mattiacci et al. (1994) reported that mechanically damaged cabbage leaves were less attractive than damaged leaves and mechanically damaged leaves treated with larval regurgitant to the parasitoid Cotesia glomerata (L.) (Hymenoptera: Braconidae). It is interesting to note that males of DBM and $C$. carnea did not react to any of the tested intact plants. Although the female $C$. carnea, used in the present study, are not predatory, we assume that the response of females is exclusively to find an oviposition site. Similarly, it was observed in the present study that C. carnea preferred to oviposit on cabbage and cauliflower, followed by broccoli and kohlrabi. To our knowledge, there appears to be no literature on the ovipositional preference of C. carnea on Brassica plants. However, previous studies on other crops indicated that irrespective of the presence or absence of other host plants, C. carnea preferred to lay more eggs on sunflower and cotton than on pigeon pea (Ballal and Singh, 1999). It is also evident from the present investigation that there-is-a-difference-in-oviposition preference-be- 
tween no-choice and free-choice experiments. This may be due to the behavior of herbivore or natural enemy toward each host plant being influenced by the presence of other host plants in the vicinity (Jalali et al., 1988).

In the present study, greater predation by $C$. carnea was observed on non-preferred host plants such as broccoli and kohlrabi, while less predation was observed on highly preferred host plants of DBM. Daane (2001) summarizes from his ecological studies on lacewings that habitat can influence on larval performance. We presume that the tested plants in our study have a wider range of phytophagous insect attacking them and there may be similar thread running through the plant groups. Moreover, host plant resistance often appears compatible with the biological control provided by generalist predators, as several studies demonstrated an additive relationship between host plant resistance and predation (see review by Trumble and Hare, 1997). There are few reports indicating heavy predation in non-preferred plants by predators, For example, $C$. carnea thrived better on the resistant variety (Panruti local) than on the susceptible variety $\left(\mathrm{MDU}_{1}\right)$ of eggplant on which $T$. ludeni is a very damaging pest (Reddy, 2001). Brown rice planthopper, Nilaparvatha lugens (Stål) (Homoptera: Delphacidae), suffered heavier predation by the spider, Lycosa pseudoannulata (Bosenberg and Strand) (Araneida: Lycosidae) on non-preferred rice cultivars (Kartohardjono and Heinrichs, 1984), and both fall armyworm, Spodoptera frugiperda (J.E. Smith) and corn earworm, Helicoverpa zea (Boddie) (Lepidoptera: Noctuidae) were more heavily attacked by Orius insidiosus (Say) (Hemiptera: Anthocoridae) on non-preferred maize varieties (Isenhour et al., 1989). This may be due to antixenosis in tesistant plants, caísing increaseô movement of prey which presumably facilitated their discovery and capture by predators (Trumble and Hare, 1997). However in contrast, two other predators, Geocoris punctipes (Say) (Hemiptera: Lygaeidae) and Podisius maculiventris (Say) (Hemiptera: Pentatomidae) were negatively affected by resistance to caterpillars in soybean (Orr and Boethel, 1986; Rogers and Sullivan, 1986) as the increase in mortality and development time occurred when these predators were reared on caterpillars that were reared on resistant soybean cultivars. There are other factors that can affect the movements of the predators. Elsey (1974) reported that predators such as Ceratomegilla (Coleomegilla) maculata and C. carnea were able to search for their prey at a much greater speed on the leaves of cotton than those of tobacco as the movements of the larvae on tobacco is seriously hampered by the glandular trichomes; the trichomes present on cotton were nonglandular and sparse and did not impede the larvae. Eigenbrode et al. (1995) reported that $C$. carnea always significantly reduced survival of DBM larvae on glossy cabbage plants but never on normal-wax plants as the greater effectiveness of pre- dators on glossy plants is apparently due to the improved mobility on glossy leaf surfaces. However, wax variation on cabbage plant surface can influence predator ( $C$. plorabunda) attachment and effectiveness (Eigenbrode et al., 1999). Wind tunnel studies by Ballal and Singh (1999) indicated that females of $C$. carnea had a significantly higher preference for both sunflower ( $\mathrm{He}$ lianthus annus L.) and cotton (Gossypium hirsutum L.), while pigeon pea (Cajanus cajan (L.) Millsp.) was least preferred. Predators have been known to respond to plant volatiles (Whitman, 1988). Romeis and Shanower (1996) observed that predators were less abundant on pigeon pea plants than on sorghum (Sorghum bicolor L.) plants, although the pest Helicoverpa armigera (Hübner) (Lepidoptera: Noctuidae) population was higher on pigeon pea.

It was observed in the present study that the DBM and $C$. carnea laid most of their eggs on the damaged cabbage plant leaves than on the leaves of intact plants. This suggests that leaves of injured plants are targeted for attack by ovipositing females as suggested by Uematsu and Sakanoshita (1993). Shiojiri et al. (2002) demonstrated that adult DBM females oyiposited preferentially on cabbage plants infested with cabbage white butterfiy, P. rapae L. (Lepidoptera: Pieridae) larvae over uninfested plants. Reddy and Guerrero (2000b) reported the attractancy of cabbage green leaf volatiles (GLVs) to mated DBM in the wind tunnel, suggesting that GLVs attract mated females to the host plant for oviposition. It is interesting to note in the present study that $C$. carnea laid more eggs on cabbage plant leaves damaged by DBM larvae. Flint et al. (1979) reported that damaged cotton plants release the terpenoid $\beta$-caryophyl-

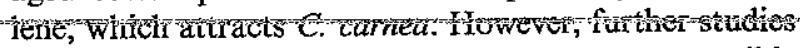
are required to identify the specific factors responsible for this strong ovipositional response of $C$. carnea toward damaged plants.

\section{Acknowledgments}

We thank Dr. Ross Miller for comments on an earlier draft of this paper. We also thank two anonymous reviewers and the editor (Dr. N.J. Mills) for their invaluable comments.

\section{References}

Ananthakrishnan, T.N., 1992. Chemical ecology in biological control. In: Ananthakrishnan, T.N. (Ed.), Emerging Trends in Biological Control of Phytophagous Insects. Oxford and IBH Publishing, New Delhi, pp. 59-67.

Anonymous, 1987. Development of diamondback moth on various host plants. Progress Report, Asian Vegetable Research and Development Center, Shañiūä, Taiwan, pp. 23=26. 
Ballal, C.R., Singh, S.P., 1999. Host plant orientational and ovipositional behavior of three species of Chrysopids (Neuroptera: Chrysopidae). Biol. Control 16, 47-53.

Bernays, E.A., Chapman, R.F., 1994. Host-Plant Selection by Phytophagous Insects. Chapman \& Hall, New York.

Canard, M., Sèméria, Y., New, T.R.R., 1984. Biology of Chrysopidae. Dr. W. Junk, The Hague.

Charleston, D.S., Kfir, R., 2000. The possibility of using Indian mustard, Brassica juncea, as a trap crop for the diamondback moth, Plutella xylostella, in South Africa. Crop Prot. 19, 455-460.

Coppel, H.C., Mertins, J.W., 1977. Biological Insect Pest Suppression. Spinger-Verlag, Berlin, Germany.

Daane, K.M., 2001. Ecological studies of released lacewings in crops. In: McEwen, P.K., New, T.R., Whittington, A. (Eds.), Lacewings in the Crop Environment. Cambridge University Press, London, pp. 338-350.

Daane K.M, Yokota, G.Y., 1997. Release methods affect egg survival and distribution of augmentated green lacewings (Chrysopidae: Neuroptera). Environ. Entomol. 26, 455-464.

Daane, K.M., Yokota, G.Y., Rasmussen, Y.D., Zheng, Y., Hagen, K.S., 1993. Effectiveness of leafhopper control varies with lacewing release methods. Calif. Agric. 47 (6), 19-23.

Eigenbrode, S.D., Kabalo, N.N., Stoner, K.A., 1999. Predation, behavior, and attachment by Chrysoperla plorabunda larvae on Brassica oleracea with different surface waxblooms. Entomol. Exp. Appl. 90, 225-235.

Eigenbrode, S.D., Moodie, S., Castagnola, T., 1995. Predators mediate host plant resistance to a phytophagous pest in cabbage with glossy leaf wax. Entomol. Exp. Appl. 77, 335-342.

Elsey, K.D., 1974. Influence of plant host on searching speed of two predators. Entomophaga 19, 3-6.

Flint, H.M., Salter, S.S., Walters, W., 1979. Caryophyllene, an attractant for the green lacewing. Environ. Entomol. 8, 1123-1125.

Hagen, K.S., 1986. Ecosystem analysis: plant cultivars (HRP), entomophagous species and food supplements. In: Boethal, D.J., Eikenbary, R.D. (Eds.), Interactions of Plant Resistance and Parasitoids and Predators of Insects. John Wiley \& Sons, New York, pp. 151-197.

Hassan, V.S.A., 1976. Untersuchungen zur verwendung des prädators Chrysopa carnea Steph. (Neuroptera: Chrysopidae) zur bekämpfungdergrunen pfirsichblattlaus Myzus persicae (Sulzer) an paprika im gewächshaus. Z. Ang. Entomol. 82, 234-239.

Isenhour, D.J., Wiseman, B.R., Layton, R.C., 1989. Enhanced predation by Orius insidiosus (Hemiptera: Anthocoridae) on larvae of Heliothis zea and Spodoptera frugiperda (Lepidoptera: Noctuidae) caused by prey feeding on resistant corn genotypes. Environ. Entomol. 18, 418-422.

Jalali, S.K., Singh, S.P., Kumar, P., Ballal, C.R., 1988. Influence of food plants on the degree of parasitism of larvae of Heliothis armigera by Cotesia kazak. Entomophaga 33, 65-71.

Kartohardjono, A., Heinrichs, E.A., 1984. Populations of the brown planthopper, Nilaparvatha lugens (Stål) (Homoptera: Delphacidae), and its predators on rice varieties with different levels of resistance. Environ. Entomol. 13, 359-365.

Kennedy, J.S., 1965: Mechanisms of host plant selection. Ann. Appl. Biol. 56, 317-322.

Mattiacci, L., Dicke, M., Posthumus, M.A., 1994. Induction of parasitoid attracting synomone in Brussels sprouts plants by feeding of Pieris brassicae larvae: role of mechanical damage and herbivore elicitor. J. Chem. Ecol. 20, 2229-2247.

McEwen, P.K., New, T.R., Whittington, A.E., 2001. Lacewings in the Crop Environment. Cambridge University Press, New York.

Miszczak, M., Niemczyk, E., 1978. Green lacewing Chrysopa carnea Steph. (Neuroptera: Chrysopidae) as a predator of European mite (Panonychus ulmi Koch) on apple trees. Part II. The effectiveness of Chrysopa carnea larvae in control Panonychus ulmi Koch. Fruit Sci. Rep. $5,21=30$ -
New, T.R.R., 1975. The biology of Chrysopidae and Hemerobiidae (Neuroptera) with reference to their usage as biocontrol agents: a review. Trans. Roy. Entomol. Soc. Lond. 127, 115-140.

New, T.R.R., 1988. Neuroptera. In: Minks, A.K., Harrewijn, P. (Eds.), Aphids: Their Biology, Natural Enemies and Control, vol. 2B. Elsevier, Amsterdam, pp. 249-258.

Nordlund, D.A., 1993. Improvements in the production system for green lacewings: a hot melt glue system for preparation of larval rearing units. J. Entomol. Sci. 28, 338-342.

Olkowski, W., Daar, S., Olkowski, H., 1991. Common Sense Pest Control. Taunton Press, Newtown, CT. pp. 66-68.

Orr, D.B., Boethel, D.J., 1986. Influence of plant antibiosis through four tropic levels. Oecologia 70, 242-249.

Pivnick, K.A., Jarvis, B.J., Slater, G.P., 1994. Identification of olfactory cues used in host-plant finding by diamondback moth, Plutella xylostella (Lepidoptera: Plutellidae). J. Chem. Ecol. 20, 1407-1427.

Reddy, G.V.P., 2001. Comparative effectiveness of an integrated pest management system and other control tactics for managing spider mite Tetranychus ludeni (Acari: Tetranychidae) on eggplant. Exp. Appl. Acarol. 25, 985-992.

Reddy, G.V.P., 2002. Plant volatiles mediate orientation and plant preference by the predator Chrysoperla carnea Stephens (Neuroptera: Chrysopidae). Biol. Control 25, 49-55.

Reddy, G.V.P., Guerrero, A., 2000a. Pheromone-based integrated pest management to control the diamondback moth, Plutella xylostella in cabbage fields. Pest Manag. Sci. 56, 882-888.

Reddy, G.V.P., Guerrero, A., 2000b. Behavioral responses of the diamondback moth, Plutella xylostella, to green leaf volatiles of Brassica oleracea subsp. capitata. J. Agric. Food Chem. 48, 60256029.

Reddy, G.V.P., Holopainen, J.K., Guerrero, A., 2002. Olfactory responses of Plutella xylostella natural enemies to host pheromone, larval frass, and green leaf cabbage volatiles. J. Chem. Ecol. 28, 131-143.

Renwick, J.A.A., Radke, C.D., 1990. Plant constituents mediating oviposition by the diamondback moth, Plutella xylostella (L.). Phytophaga 3, 37-46.

Rogers, D.J., Sullivan, M.J., 1986. Nymphal performance of Geocoris punctipes (Hemiptera: Lygaedae) on pest-resistance soybeans. Environ. Entomol. 15, 1032-1036.

Romeis, J., Shanower, T.G., 1996. Arthropod natural enemies of Helicoverpa armigera (Hübner) (Lepidoptera: Noctuidae) in India. Biocontrol Sci. Technol. 6, 481-508.

Sant, P.S., Dilbagh, S., Singh, S.P., Singh, D., 1982. Influence of cruciferous host plants on the survival and development of Plutella xylostella L. J. Res. PAU India 19, 100-104.

Shiojiri, K., Takabayashi, J., Yano, S., Takafuji, A., 2002. Oviposition preferences of herbivores are affected by tritrophic interaction webs. Ecol. Lett. 5, 186-192.

Steel, R.J.D., Torrie, J.H., 1980. Principles and Procedures of Statistics, second ed. McGraw-Hill, New York.

Tabashnik, B.E., 1994. Evolution of resistance to Bacillus thuringiensis. Annu. Rev. Entomol. 39, 47-79.

Tabashnik, B.E., Schwartz, J.M., Finson, N., Johnson, M.W., 1992. Inheritance of resistance to Bacillus thuringiensis in diamondback moth (Lepidoptera: Plutellidae). J. Econ. Entomol. 85, 1046-1055.

Talekar, N.S., Shelton, A.M., 1993. Biology, ecology and management of diamondback moth. Annu. Rev. Entomol. 38, 275-301.

Thomas, M.B., Waage, J.K., 1996. Integration of Biological Control and Host Plant Resistance Breeding-a Scientific and Literature Review. Technical Centre for Agricultural and Rural Co-operation of the European Union (CTA), Wageningen, Netherlands. p. 99.

Trumble, J.T., Hare, J.D., 1997. Tritrophic interactions in the management of Spodoptera exigua on celery. In: Bondari, K. (Ed.), Recent Developments in Entomology. Research Signpost, Trivandrum, pp- $-117=134$ - 
Uematsu, H., Sakanoshita, A., 1993. Micro-distribution of eggs of diamondback moth, Plutella xylostella, on intact and injured cabbage plantlets. Jpn. J. Appl. Entomol. Zool. 37, 1-3.

Vet, L.E.M., Dicke, M., 1992. Ecology of infochemicals use by natural enemies in tritropic context. Annu. Rev. Entomol. 37, 141-172.

Whitman, D., 1988. Allelochemical interactions among plants, herbivores and their predators. In: Barbosa, P., Letourneau, D. (Eds.),
Novel Aspects of Insect-Plant Interactions. Wiley, New York, pp. 11-64.

Zhu, J., Cossé, A.A., Obrycki, J.J., Boo, K.S., Baker, T.C., 1999. Olfactory reactions of the twelve-spotted lady beetle, Coleomegilla maculata and the green lacewing, Chrysoperla carnea to semiochemicals released from their prey and host plant: electroantennogram and behavioral responses. J. Chem. Ecol. 25, 1163-1177. 